\title{
DESIGN OF A GLUE APPLYING MACHINE
}

\author{
Balázs BEKŐ ${ }^{1}$, Ferenc SZIGETI ${ }^{2}$ \\ University of Nyíregyháza, Department of Physics and Production Engineering, \\ Nyíregyháza, Hungary \\ ${ }^{1}$ bekobalazs2@gmail.com \\ ${ }^{2}$ szigeti.ferenc@nye.hu
}

\begin{abstract}
Glue applying machines allow the application of glue to a surface during production. The purpose of this work is to solve certain problems with the development of a new machine. In this paper, measurements and tests made before designing the new machine will be presented. The parts of the machine that that have been designed will also be presented as well as a simulation by finite element method conducted for a part of the machine's support frame that has a critically dangerous cross-section.
\end{abstract}

Keywords: glue application, glue application measurement, finite element test, design of a machine.

\section{Introduction}

I wrote my thesis at the Eissmann Group Automotive Hungaria Kft. [1] one of the companies that participates in a dual training program together with the University of Nyíregyháza.

This topic was chosen because I became interested in glue application technologies implemented by this company and wished to improve, with suggestions, the quality and economic efficiency of glue application.

First of all, the characteristics of glue application machines, and the advantages and disadvantages of their use: I specifically discuss the Fortuna ECOL 200 machine, which was the object of these tests. The identified problems found with this machine will be described, and the tests performed regarding glue application will be detailed, as well as the changes in construction and proposed solutions to solve the identified problems.

The purpose of this work is to solve the existing problems by redesigning the machine to allow for a more consistent application of the glue, reduce the amount of glue used and to make it easier to assemble, maintain and setup.

\section{Problems with the Fortuna ECOL 200}

The faults of the Fortuna ECOL 200 [2] are: patchy, inconsistent application of glue, and a high amount of glue $(2,8 \mathrm{dl})$ that remains in the tray at the end of each shift. This corresponds to a loss of 250.000.- Ft per a year if we consider only one such machine. Additionally, at the end of each shift the worker should be able to easily remove the cylinder that applies the glue since it has to be cleaned. When working with this machine, the cylinder cannot be removed by itself, only together with its axis and the connected gear, a considerable weight. Yet another problem is the difficulty in setting the correct distance between the two axes. It is currently complicated and time consuming.

\section{Glue application measurments}

The difference between spraying the adhesive and applying it by machine was measured, and it was proved that to apply the glue to a leather surface with a blast gun comes there is much loss of material compared to application by machine. Table 1 . shows that nearly $60 \%$ of all the blown adhesive is wasted. In the case of one blower cabin, the financial loss was around 700,000 Ft per year, and there are several such cabins at the company.

Based on the tests, it is preferable to use an adhesive application machine instead of the cabins, at least for those blowing cabins that apply glue 
Table 1. The loss of glue with blowing

\begin{tabular}{|c|c|c|c|}
\hline \multicolumn{4}{|c|}{ Blowing 35 products } \\
\hline $\begin{array}{c}\text { Weight of } \\
\text { the glue on } \\
\text { the leather } \\
\text { (g) }\end{array}$ & $\begin{array}{c}\text { Missing glue from } \\
\text { the container of } \\
\text { the pistol } \\
\text { (g) }\end{array}$ & Loss & Loss \\
\hline 29.64 & 69.61 & (g) & (\%) \\
\hline
\end{tabular}

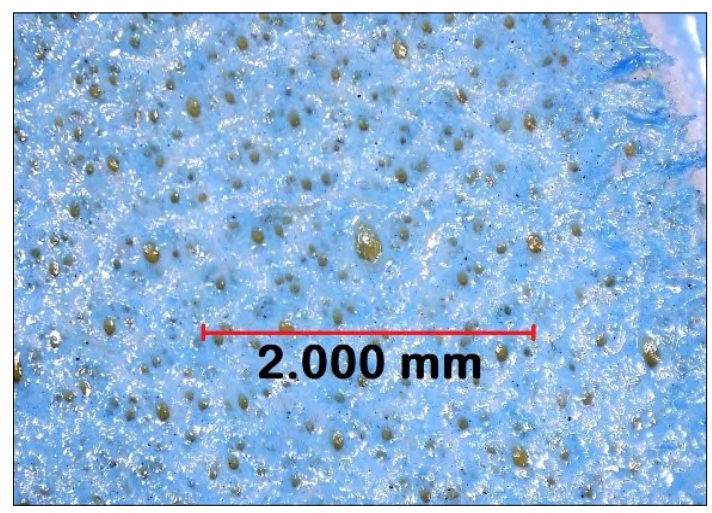

Figure 1. Photo of leather that is glued by blowing pistol

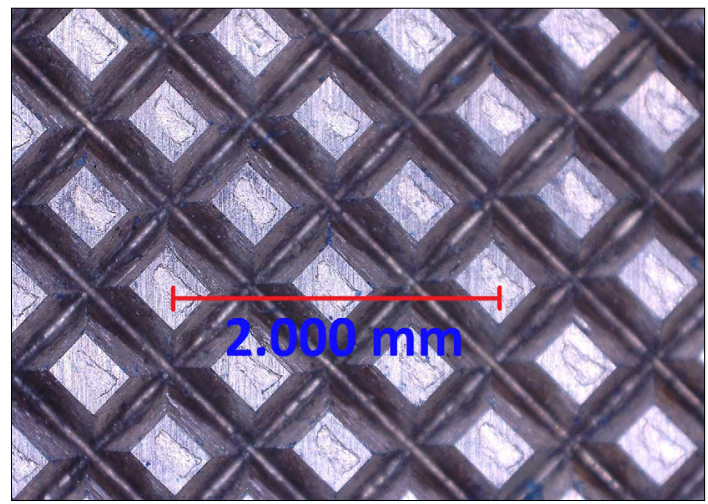

Figure 2. Cylinder with knurled surface under microscope

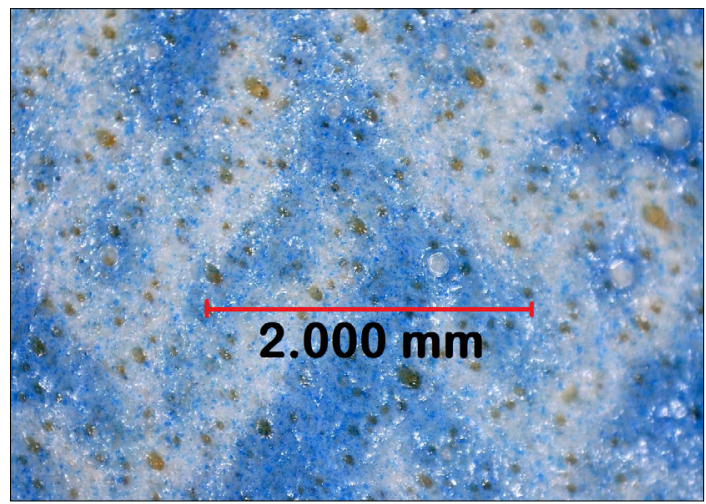

Figure 3. Photo of leather that is glued by the knurledsurface cylinder under the microscope to leather that hasn't been stitched yet. Adhesive application machines cannot process a stitched leather surface since that leather is usually sewn into complex shapes (such as the skirt of a car's gear shift lever for example). Moreover, blasting should be applied when applying adhesive to injection molded plastic parts.

Next microscopic photographs were obtained in 32x magnification with a DNT DigiMicro Profi microscope found in the company's laboratory. The purpose of the study was to determine which type of surface pattern and design of cylinder results in a more uniform distribution of the adhesive on the leather surface. The tests showed that if there is less coarseness on the cylinder's surface, it will result in a more uniform adhesive application. Correct surface coarseness is required because that is a condition for the adhesive to remain on the cylinder.

Figure 1. shows a piece of leather that was glued by use of a blowing pistol. The dispersion is good and relatively uniform. Figure 2. shows the surface of the Fortuna ECOL 200's original production cylinder's knurled surface under the microscope. Figure 3. shows the adhesive applied to the leather by this cylinder.

One can see on these picture that the knurled surfaced cylinder cannot assure an even dispersion on the leather surface. After applying glue with this kind of machine, a worker has to smooth the leather with a hand roller to achieve a more even distribution.

There is a third method for applying glue at this company, by a different kind of equipment that uses a sandblasted steel application cylinder capable of spreading the glue as evenly as the glue blowing technique or a combination of the Fortuna and the hand roller, but such cylinders are a lot more expensive to produce.

\section{Design of the new machine to re- place the Fortuna}

Here I present the new equipment design, its components and their functions. There is a dangerous cross-section on one of the components and a static load finite element simulation is presented, designed to determine the necessary material quality for that component. The redesigned glue application machine is shown in Figure 4. (drawn with SolidWorks software).

The $220 \mathrm{~W}$ electric motor and the $114 \mathrm{~mm}$ diameter and $200 \mathrm{~mm}$ long steel roller are taken over from Fortuna to this machine, but this new 
cylinder no longer does both the scooping and the applying of the adhesive, it only picks it up. It then transfers the adhesive to a rubber roller which applies it, thus ensuring a more uniform adhesive application than that possible with the Fortuna's knurled steel cylinder. With this method the application process resembles flexo printing [3] since there is also a hard surfaced cylinder that transfers the adhesive to another, elastic roller. The removal of excess adhesive in the new construction can be adjusted more precisely than with the Fortuna ECOL 200 (point 3.3).

The components of the redesigned equipment were designed in SolidWorks 3D designer software after numerous measurements, scaling and sketching. The individual parts were joined together in an assembly file (Figure 4.). The model includes all components as well as connecting and driving elements (except for the timing belt).

\subsection{The glue holding tray}

The tray was designed so that if there is $3 \mathrm{~mm}$ thick silicon lining in all directions, the adhesive roller must be $2 \mathrm{~mm}$ away from each side of the tray (Figure 5.). This minimizes the amount of glue that remains in the tray at the end of each shift. In order to make silicone casting easier another tray was designed that should be placed on top of the "main" tray and left there until the sili-

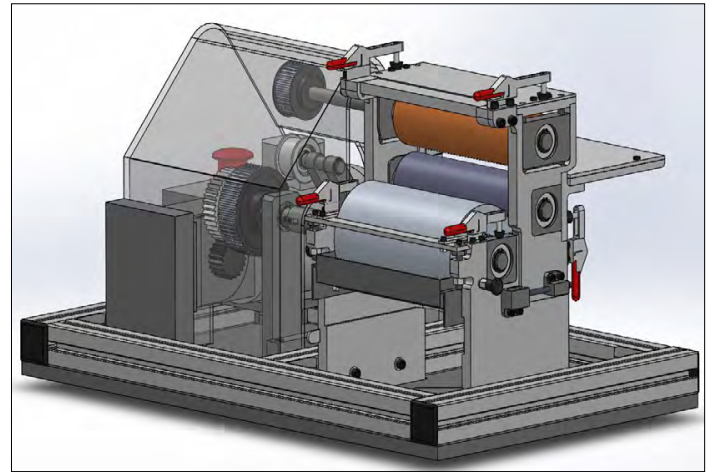

Figure 4. The construction in the SolidWorks



Figure 5. The glue holding tray cone binds. Therefore this other tray must be at a $3 \mathrm{~mm}$ distance from the "main" glue holder tray in every direction.

\subsection{Setting the distance between the axes}

The distance between the axis of the two upper rollers was designed to be adjusted by rotating the threaded spindles that are in the holes inside the upper roller bearing housings. The distance between the glue picker and the rubber roller (between those there is friction drive) can be adjusted without changing the distance between the two top rollers. This is designed to accommodate the taper housing of the applicator and the counter roller in the upper brackets; the entire upper bracket can be moved by adjusting the spindle and the spindle can be fastened to the nut in the optimal position (Figure 6.).

\subsection{The glue puller plate}

The amount of adhesive on the cylinder can be controlled by a puller plate (Figure 7.). The glue puller plate that was designed will provide a much more accurate setting compared to the ECOL 200 plate. This has to be set vertically, not horizontally. Since the plate is $20 \mathrm{~mm}$ above the center line of the picker roller, a vertical displacement of $1 \mathrm{~mm}$ results in only a few tenths of a $\mathrm{mm}$ horizontally (Figure 8.). So the thickness of

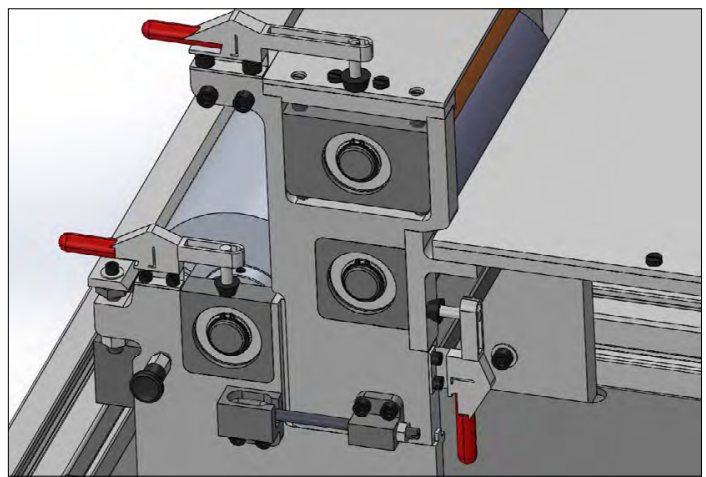

Figure 6. Setting the distance

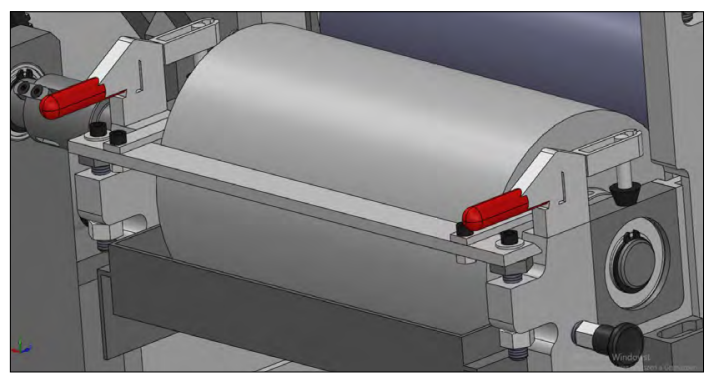

Figure 7. The glue puller plate 
the adhesive film to be applied can be adjusted much more precisely than before.

\subsection{The clutch}

Currently, at the end of each shift at Fortuna, when cleaning the applying/picker roller, the worker has to take out the entire axis with the gear wheel on it. The new construction allows the cylinder to be removed without displacing other drive elements and that is achieved by a clutch within a spring.

The spring is equipped with a clutch casing, which can be manually pulled out by the worker while rotating the shaft of the cylinder by means of a 15-wrench, it will no longer lock in and the shaft can be lifted. Then the cylinder is removable by its bearing housings, without displacement of the other drive elements (Figure 9.).

\subsection{Mechanical simulation with finite ele- ment method}

There is a critical cross section on the chassis of the machine (Figure 10.). A finite element simulation for static load is presented, which allows for the correct selection of material quality for the component.

\subsection{The rollers}

One of the problems with the operation of the Fortuna equipment was the uneven glue application. By choosing the right roller, this problem can be solved. In the gupfo.com online store I found the right kind of rollers for the machine. It is advisable to apply rubber to the applicator because it does not absorb the glue, yet it is flexible, and for the counter-roller cheaper sponge can also be used as it does not come into contact with the adhesive.

A hard metal or plastic tray was used for flexible cylinders, on which the leather is temporarily glued, so in theory there should be no patchiness (because if the worker pushes the skin onto the tray, it won't lose its shape).

\section{Summary}

We investigated and described the problems with the Fortuna ECOL 200 glue applying machine; measurements and tests were performed, and with the help of the results I have designed a machine that meets the needs of the plant.

Installation documentation for the new construction has also been prepared [4]. Based on the design documentation, the new glue application machine can be manufactured.

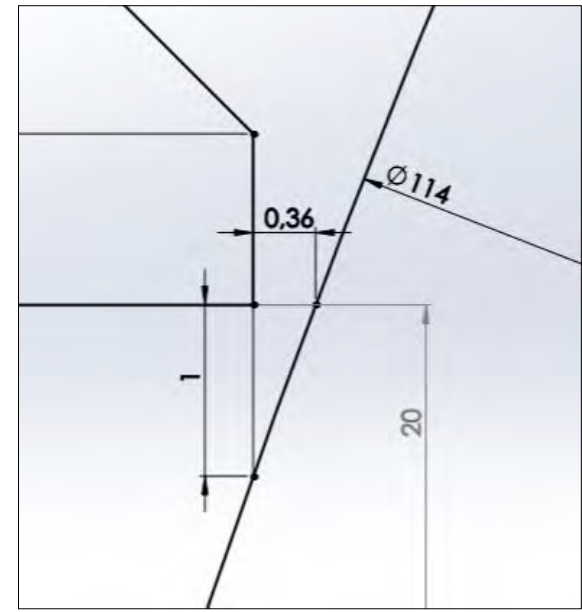

Figure 8. Close sketch of the puller plate

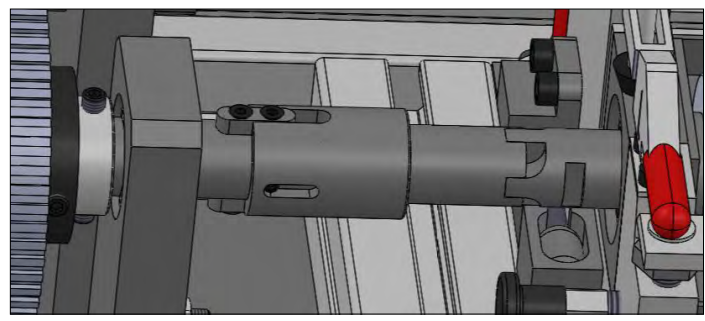

Figure 9. The clutch

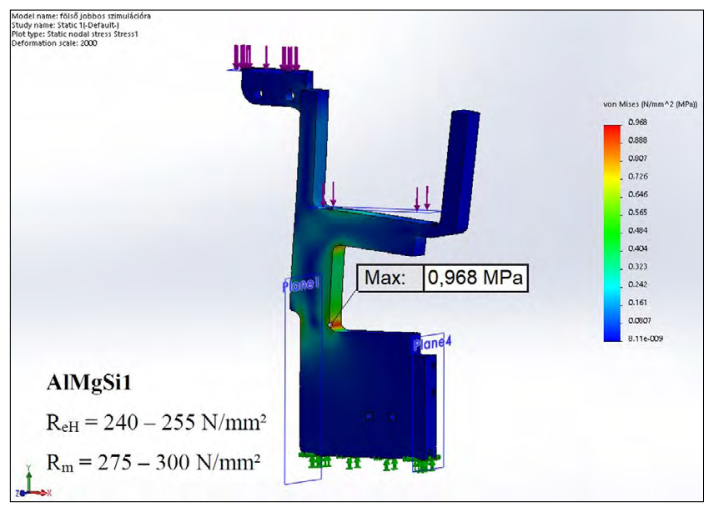

Figure 10. Stress state obtained from mechanical simulation

\section{References}

[1] Eissmann Automotive, History

https://www.eissmann.com/en/the-company/history.html

[2] A Fortuna ECOL 200 gépkönyve

[3] Magyar nyomdász, A flexó nyomtatás https://www.magyarnyomdasz.hu/a-flexo-nyomtatas

[4] Jánossy Gy., Zsidai L., Kári-Horváth A.: Szereléstechnológiák. Nemzeti Munkaügyi Hivatal, 2014. 